\title{
Patient activation in individuals with type 2 diabetes mellitus: associated factors and the role of insulin
}

This article was published in the following Dove Medical Press journal:

Patient Preference and Adherence

\section{Heidi A van Vugt ${ }^{1,2, *}$ \\ Anne Meike Boels 1 ,* \\ Inge de Weerdt ${ }^{2}$ \\ Eelco JP de Koning ${ }^{3}$ \\ Guy EHM Rutten'}

'Julius Center for Health Sciences and Primary Care, University Medical Center Utrecht, Utrecht University, 3508 GA Utrecht, Utrecht, the Netherlands; ${ }^{2}$ Dutch Diabetes Federation, Amersfoort 3818 LE, the Netherlands; ${ }^{3}$ Department of Medicine, Leiden University Medical Center, 2300 RC Leiden, the Netherlands

*These authors contributed equally to this work
Correspondence: Anne Meike Boels Julius Center for Health Sciences and Primary Care, University Medical Center Utrecht, Str 6.13I, PO Box 85500, 3508 GA, Utrecht, the Netherlands Tel +3I 887568156

$\mathrm{Fax}+31887568099$

Email a.m.boels-2@umcutrecht.nl
Aim: This study explored the relationship between insulin use and patient activation (a person's internal readiness and capabilities to undertake health-promoting actions) in individuals with type 2 diabetes mellitus and aimed to identify demographic, clinical and psychosocial factors involved in patient activation.

Methods: In this cross-sectional study, baseline data from a Dutch nationwide study were analyzed. Patient activation was assessed with the Patient Activation Measure 13. A linear mixed model was used to take clustering into account.

Results: In total, 1,189 persons were included (310 of whom were on insulin), enrolled via 47 general practices and six hospitals. Their mean Patient Activation Measure 13 score was $59 \pm 12$. We found no association between insulin therapy and patient activation. In the multivariable analysis, individuals with a better health status, very good or very poor social support (vs good social support), individuals who felt they had greater control over their illness and those with a better subjective understanding of their illness showed higher patient activation. Individuals with a lower educational level and those who expected their illness to continue showed a lower activation level. Conclusion: Patient activation does not differ between individuals with type 2 diabetes mellitus on insulin therapy and those on other therapies.

Keywords: provider-patient communication, patient participation in health care, social support, patient activation, insulin therapy, psychological aspects, self-management

\section{Introduction}

Over the past century, chronic diseases have emerged as the major health problem worldwide. ${ }^{1}$ Due to the differential requirements of chronic diseases compared to acute diseases, health care systems are transforming and becoming more patient-centered. ${ }^{2}$ In these patient-centered health care systems, patients are expected to engage in their own care; they are encouraged to take more responsibility, to obtain information on their disease and to consciously choose between treatment options. ${ }^{3,4}$ Physicians also need to coach their patients on how to become an effective participant in their own disease management. ${ }^{1,3}$ To be in a position to effectively participate, patients need adequate knowledge, motivation, skills and confidence. ${ }^{5,6}$ These prerequisites for managing a health condition are captured by the concept "patient activation". Patient activation refers to one's internal readiness and capabilities to undertake healthpromoting actions. ${ }^{7}$

Individuals with type 2 diabetes mellitus require sufficient knowledge, motivation, skills and confidence to properly manage their disease - in other words, they need a sufficient level of "activation". 
There are four stages of patient activation..$^{5}$ In the first stage, the individual believes that an active role is important for disease management. In the second stage, he or she has the knowledge and the confidence to take action; in the third stage, the patient actually takes action. Finally, in the fourth stage, the patient is able to maintain adequate behavior, even when under stress. ${ }^{3,5}$

Assuming a close relationship between patient activation and self-care, ${ }^{3,8}$ the former could be of paramount importance in improving diabetes care. A low level of patient activation is not only associated with unhealthy behavior (eg, obesity) and increased health care utilization (eg, emergency department visits) in a broad group of patients but has also been linked to the development of chronic diseases. ${ }^{9}{ }^{10}$ In individuals with type 2 diabetes mellitus, a higher level of patient activation is also associated with the proportion reaching their $\mathrm{HbAlc}$ target level. ${ }^{6}$ To achieve this HbA1c target, people may need to change their lifestyle or take oral antihyperglycemic agents. Both activities require a minimum level of activation. Eventually, $30 \%$ of the individuals with type 2 diabetes mellitus will require insulin therapy. ${ }^{11}$ These individuals also need to regularly monitor their blood glucose, to inject insulin correctly, to adjust insulin dosages in accordance with physical activity and carbohydrate intake and to be able to manage and handle hypoglycemic symptoms. Therefore, one could argue that individuals on insulin therapy might have a higher level of activation. On the other hand, one could also maintain that individuals on insulin therapy might in fact be less activated, since they failed to achieve metabolic control using lifestyle advice and antihyperglycemic agents and, therefore, had to initiate insulin therapy.

Previous studies of patient activation in type 2 diabetes mellitus demonstrated that a patient's educational level, disease knowledge, trust in the treating physician, participatory decision making, social support from friends, physical health status, blood pressure and cholesterol and glycemic control were all positively associated with patient activation, whereas a negative association was found for age, hospitalization, emergency department visits, depression, body mass index (BMI) and macrovascular complications. ${ }^{3,4,9,12-21}$ Studies on insulin use have reported contradictory results: one study found that individuals on insulin therapy had a lower level of patient activation, ${ }^{12}$ whereas another study found no association between patient activation and insulin use. ${ }^{13}$

This study was undertaken to explore the relationship between insulin use and patient activation in individuals with type 2 diabetes mellitus and to identify other demographic, clinical and psychosocial factors involved in patient activation.

\section{Materials and methods Study design}

We analyzed baseline data from a longitudinal study that assessed a structured diabetes consultation model. ${ }^{14}$ This consultation model was developed by the Dutch Diabetes Federation to facilitate person-centered diabetes care including shared decision making. ${ }^{14}$ The Medical Ethical Research Committee of the University Medical Center Utrecht concluded that ethical approval was unnecessary since the study did not fulfill the criteria for medical human scientific research under Dutch legislation. All study procedures were in accordance with the Declaration of Helsinki. All participants provided written informed consent.

\section{Setting}

Between November 2015 and February 2017, individuals with diabetes mellitus were included from both primary care (general practices) and secondary care facilities (hospital outpatient clinics). The study was conducted in 47 general practices and six hospitals throughout the Netherlands.

\section{Participants}

In the original study, adults with type 1 or type 2 diabetes were included via participating general practices and outpatient clinics. Eligible participants were Dutch-speaking adults aged $\geq 18$ years, who were capable of filling out questionnaires and mentally able to participate. There were no exclusion criteria. For the purposes of this study, we included all type 2 diabetes mellitus participants who completed the baseline questionnaires and had a valid Patient Activation Measure 13 (PAM-13) score available (explained in the "Data collection and measures" section).

\section{Data collection and measures}

Participants were asked to complete questionnaires before their annual conversation (structured by the diabetes consultation model) took place. Patients were able to complete questionnaires either online or on paper, based on their personal preference. In this study, we used data from the following questionnaires:

- The PAM-13, a 13-item measure that assesses patient self-reported knowledge, skills and confidence in selfmanagement. ${ }^{3,5}$ Item scores range from 0 to 4 , with 0 "not applicable"; 1 "strongly disagree"; 2 "disagree"; 3 "agree" and 4 "strongly agree". A mean PAM-13 score is then transformed into a score ranging from 0 to 100 , where higher scores represent higher activation. PAM-13 scores were calculated according to the Insignia 
Health guidelines. ${ }^{15}$ Individuals who answered fewer than seven questions were excluded, as were those who answered all 13 questions with "I strongly disagree" or "I strongly agree". Subsequently, all individuals with a valid PAM-13 score were assigned to one of the four stages of activation, based on the Insignia Health guidelines. ${ }^{15,16}$

- The EuroQol 5D (EQ-5D), a generic health status questionnaire that covers mobility, self-care, daily activities, pain/discomfort and anxiety/depression. All five items are rated from no problems to severe problems, with a total score ranging from -0.33 to 1.00 ; the lower the score, the worse the health status. ${ }^{17}$

- The Audit of Diabetes-Dependent Quality of Life (ADDQoL) measures the impact and importance of diabetes and its treatment on quality of life. The questionnaire consists of 19 questions for which an average weighted impact is calculated, ranging from -9 to 3 ; lower scores represent a negative influence of diabetes on quality of life. ${ }^{18}$

- The Brief Illness Perception Questionnaire (BIPQ) measures illness perceptions on the following eight dimensions: 1) consequence, 2) timeline, 3) personal control, 4) treatment control, 5) identity, 6) illness concern, 7) coherence and 8) emotional representation. All dimensions are rated on a $0-10$ scale. ${ }^{19}$

- The five-item Problem Areas In Diabetes scale (PAID-5), a questionnaire on diabetes-related distress. Items are rated from 0 (not a problem) to 4 (serious problem). A total score of $\geq 8$ may indicate severe diabetes-related distress. $^{20}$

- From the Summary of Diabetes Self-Care Activities Measure (SDSCA), we only used the item that assesses smoking status (Have you smoked a cigarette - even one puff - during the past seven days?), which can be answered with yes or no. ${ }^{21}$

- To assess social support, we evaluated the answer to the following statement: "People around me support me when I have health-related problems" to which people could reply: 1) strongly agree (ie, very good social support), 2) agree (ie, good social support), 3) disagree (ie, poor social support) or 4) strongly disagree (ie, very poor social support).

A study-specific questionnaire assessed sex, level of education, diabetes duration, insulin use, alcohol use (yes/no and daily number of alcoholic beverages) and diabetesrelated complications. Educational level was categorized into the following three levels: low (no education, primary school only or lower education), intermediate or high (higher education or university). Macrovascular complications were classified as being present when a patient had a history of myocardial infarction, angina pectoris or stroke. Microvascular complications were classified as being present when a patient reported a history of kidney problems, tingling and/or numbness of hands, legs or feet or diabetes-related eye problems.

The following data were extracted from electronic medical files: age, type of diabetes, SBP, length, weight and most recently measured $\mathrm{HbA} 1 \mathrm{c}$ and low-density lipoprotein (LDL) cholesterol.

\section{Analyses}

To analyze differences between patients with and without insulin therapy, we performed a Student's $t$-test for continuous normally distributed data, Mann-Whitney $U$ test for continuous non-normally distributed data and a chi-squared test for categorical data. Because the exclusion of patients with missing values can result in reduced statistical power and can potentially lead to biased results, missing data were handled with multiple imputations (five imputed data sets, assuming missing data were at random).

Since patients' answers and biomedical outcomes may be correlated if they are treated within the same center (either within a general practice or a hospital), the data have a hierarchical two-level structure. Therefore, we used linear mixed models with random intercepts for each center. All explanatory variables were included as fixed effects. First, we investigated the association between the PAM-13 score and insulin use in a univariable analysis. For the multivariable analyses, we included the following potential confounders due to their known association with PAM-13: age, level of education, presence of macrovascular complications, social support, BMI, blood pressure, HbA1c, cholesterol, EQ-5D, BIPQ and ADDQoL., 12,13,22-27 We included the following potential confounders from a clinical perspective: smoking and alcohol use (since unhealthy behavior was associated with low patient activation), ${ }^{9}$ diabetes duration (since patient activation is not stable over time) ${ }^{28}$ and PAID-5 (since we hypothesized that individuals on insulin therapy could experience greater diabetes-related distress, which might influence patient activation). ${ }^{29}$ We did not include sex as a confounder, because previous research did not identify differences in patient activation between men and women with type 2 diabetes mellitus. ${ }^{13}$ Assumptions of the model were assessed using residual analyses.

To further scrutinize the differences between individuals on insulin therapy and those on other therapies, we investigated the differences between the two groups by including interaction terms for insulin with all variables in the model. 
Data were analyzed using SPSS version 21.0 (IBM Corporation, Armonk, NY, USA). A $P$-value of $<0.05$, or in regression analyses a $95 \% \mathrm{CI}$ of a $\beta$ that does not include zero, was considered statistically significant.

\section{Results}

Of the 1,487 participants, 1,367 were diagnosed with type 2 diabetes mellitus. Of them, 68 did not fill out the questionnaires; another 110 were excluded because they did not provide a valid PAM-13 score: 33 participants answered all questions with "strongly agree", one person answered all questions with "strongly disagree" and 77 individuals answered less than seven questions. There were no statistically significant differences in age, BMI, SBP, LDLcholesterol or $\mathrm{HbAlc}$ between the 178 excluded and the 1,189 included participants (no other background variables were available since not all excluded participants filled out the questionnaires).

Before imputation, $2.5 \%$ of all values (both PAM-13 scores and confounders) were missing (at random) and were distributed among 327 cases (27.5\%). The PAM-13 had a good internal consistency (Cronbach's $\alpha=0.827$ ).

Table 1 shows the characteristics of the study population. Insulin users were more often women, more often smokers, but reported drinking alcohol less often. Cardiometabolic control among insulin users was worse, and they reported more diabetes-related complications. Moreover, diabetes and its treatment had a bigger impact on their quality of life, their health status was worse, they perceived diabetes as a more serious threatening disease and had more diabetes-related distress compared to people not on insulin therapy. However, PAM-13 scores did not differ between the groups.

In the univariable analysis, there was no statistically significant association between insulin use and PAM-13 score: $\beta-0.76,95 \% \mathrm{CI}-2.35$ to $0.82, P=0.346$ (reference category is "no insulin use"). Table 2 shows the results of the multivariable analysis. As in the univariable analysis, there was no statistically significant association between insulin use and the PAM-13 score. A better health status (EQ-5D), more perceived personal control (BIPQ personal control dimension: "How much control do you feel you have over your illness?"), more coherence (BIPQ coherence dimension: "How well do you feel you understand your illness?") and both very good and very poor social support (compared to moderate support) were independently positively associated with patient activation. A low educational level and a perceived longer duration of type 2 diabetes mellitus (BIPQ timeline dimension: "How long do you think your illness will continue?") were independently negatively associated with the PAM-13 score. Residual analysis of this multivariable two-level linear mixed model showed no deviation from distributional assumptions and no heteroscedasticity.

In the stratified analysis, three out of the 22 tested interactions with insulin were statistically significant. For the EQ-5D, the main effect was a 4.37 increase in patient activation for a one-point increase in EQ-5D ( $P=0.014$; Table 2), while the relation between EQ-5D and patient activation for those on insulin was lower than for the non-insulin users and possibly negative ( $\beta$ interaction: $-10.08, P=0.15$ ).

The second statistically significant interaction was for the BIPQ treatment control dimension ("How much do you think your treatment can help your illness?"): $\beta$ main effect: $0.26, P$-value $=0.144 ; \beta$ interaction: $0.88, P$-value $=0.048$. This implies that for those on insulin therapy, greater perceived treatment control is more positively associated with patient activation compared to those not on insulin therapy.

Finally, for social support, the $P$-value for the interaction of insulin with very good social support was 0.011 , with the following estimated marginal means for patient activation: 59.42 for those using insulin and 62.57 for those not on insulin ( $\beta$ main effect: $4.64 ; \beta$ interaction: -4.69$)$.

\section{Discussion}

We explored the relationship between insulin use and patient activation. We hypothesized that individuals with type 2 diabetes mellitus on insulin therapy could have either a higher or a lower level of activation. However, in a large group of people with type 2 diabetes mellitus, we found no difference in patient activation between those individuals using or not using insulin therapy. However, among insulin users, patient activation was partly explained by different determinants.

The absence of an association between insulin therapy and patient activation could be due to bias inherent in our study design (explained in the "Strengths and limitations" section) or could be truly absent. Since patient activation reflects a person's internal motivation and ability to engage in health-promoting behavior, an external factor such as insulin therapy may not alter a person's knowledge, motivation, skills and confidence; ${ }^{7}$ insulin therapy and patient activation could therefore be unrelated.

\section{Strengths and limitations}

Unfortunately, we were not able to take insulin regimen into account. Insulin regimens differ considerably in terms of self-management demands..$^{30,31}$ For example, an insulin regimen consisting of one daily injection with long-acting 
Table I Characteristics of the study population showing differences between those on insulin therapy and those not on insulin therapy

\begin{tabular}{|c|c|c|c|c|}
\hline & All & Insulin use & No insulin use & $P$-value \\
\hline & $N=1,189$ & $n=310(26.1 \%)$ & $\mathrm{n}=879(73.9 \%)$ & \\
\hline Age (years), mean \pm SD & $66 \pm 10$ & $66 \pm 10$ & $66 \pm 10$ & 0.856 \\
\hline Sex: female, n (\%) & $490(4 I .2)$ & $145(46.8)$ & $345(39.2)$ & 0.021 \\
\hline $\begin{array}{l}\text { Educational level: } \mathrm{n}(\%) \\
\text { Low } \\
\text { Middle } \\
\text { High }\end{array}$ & $\begin{array}{l}399(33.6) \\
535(45.0) \\
255(18.9)\end{array}$ & $\begin{array}{l}\text { II I (35.8) } \\
\text { I } 45(46.8) \\
54(17.4)\end{array}$ & $\begin{array}{l}289(32.9) \\
390(44.4) \\
200(22.8)\end{array}$ & 0.150 \\
\hline Smoking: yes, n (\%) & $172(14.5)$ & $58(18.7)$ & $114(13.0)$ & 0.016 \\
\hline Alcohol: yes, n (\%) & $560(47.1)$ & $117(37.7)$ & $443(50.4)$ & $<0.001$ \\
\hline Diabetes duration (years), median (IQR) & $10(11)$ & $16(12)$ & 7 (9) & $<0.001$ \\
\hline Treatment in primary care, $\mathrm{n}(\%)$ & $\mathrm{I}, 043(87.7)$ & $174(56.1)$ & $869(98.9)$ & $<0.001$ \\
\hline Microvascular complications, $\mathrm{n}(\%)$ & $430(36.2)$ & $153(49.4)$ & $277(31.5)$ & $<0.001$ \\
\hline Macrovascular complications, n (\%) & $298(25.1)$ & $97(31.3)$ & $201(22.9)$ & 0.004 \\
\hline BMI $\left(\mathrm{kg} / \mathrm{m}^{2}\right)$, median $(\mathrm{IQR})$ & $29(7)$ & $30(7)$ & $29(7)$ & $<0.001$ \\
\hline $\mathrm{SBP}(\mathrm{mmHg})$, mean $\pm \mathrm{SD}$ & $137 \pm 17$ & $139 \pm 19$ & $136 \pm 16$ & 0.009 \\
\hline $\mathrm{HbAlc}(\%)$, mean $\pm \mathrm{SD}$ & $7.0 \pm 1.0$ & $7.7 \pm 1.1$ & $6.8 \pm 0.7$ & $<0.001$ \\
\hline $\mathrm{HbAlc}(\mathrm{mmol} / \mathrm{mol})$, mean $\pm \mathrm{SD}$ & $53 \pm 11$ & $61 \pm 12$ & $50 \pm 8$ & \\
\hline $\mathrm{LDL}$ cholesterol (mmol/L), mean $\pm \mathrm{SD}$ & $2.4 \pm 0.9$ & $2.4 \pm 0.9$ & $2.4 \pm 0.9$ & 0.760 \\
\hline PAM-I3 score, mean \pm SD & $59 \pm 12$ & $58 \pm 12$ & $59 \pm 12$ & 0.258 \\
\hline $\begin{array}{l}\text { PAM level, n (\%) } \\
\text { I } \\
2 \\
3 \\
4\end{array}$ & $\begin{array}{l}175(14.7) \\
266(22.4) \\
561(47.2) \\
187(15.7)\end{array}$ & $\begin{array}{l}51(16.5) \\
73(23.5) \\
139(44.8) \\
47(15.2)\end{array}$ & $\begin{array}{l}124(14.1) \\
193(22.0) \\
422(48.0) \\
140(15.9)\end{array}$ & 0.639 \\
\hline EQ-5D, median (IQR) & $0.84(0.23)$ & $0.8 \mathrm{I}(0.28)$ & $0.84(0.23)$ & $<0.001$ \\
\hline \multicolumn{5}{|l|}{$\mathrm{BIPQ}$, mean $\pm \mathrm{SD}$} \\
\hline I. Consequence & $4.2 \pm 2.7$ & $5.6 \pm 2.4$ & $3.7 \pm 2.6$ & $<0.001$ \\
\hline 2. Timeline & $8.5 \pm 2.6$ & $9.5 \pm 1.4$ & $8.1 \pm 2.8$ & $<0.001$ \\
\hline 3. Personal control & $6.8 \pm 2.1$ & $7.1 \pm 1.7$ & $6.6 \pm 2.3$ & $<0.001$ \\
\hline 4. Treatment control & $7.4 \pm 2.2$ & $7.9 \pm 1.8$ & $7.3 \pm 2.3$ & $<0.001$ \\
\hline 5. Identity & $3.6 \pm 2.6$ & $5.0 \pm 2.5$ & $3.1 \pm 2.5$ & $<0.001$ \\
\hline 6. Illness concern & $4.8 \pm 2.9$ & $5.8 \pm 2.7$ & $4.4 \pm 2.9$ & $<0.001$ \\
\hline 7. Coherence & $6.9 \pm 2.2$ & $7.4 \pm 1.7$ & $6.8 \pm 2.4$ & $<0.001$ \\
\hline 8. Emotional representation & $3.1 \pm 2.9$ & $4.6 \pm 3.0$ & $2.6 \pm 2.6$ & $<0.001$ \\
\hline ADDQoL, median (IQR) & $-0.40(1.17)$ & $-1.06(1.64)$ & $-0.25(0.84)$ & $<0.001$ \\
\hline $\begin{array}{l}\text { Social support, n (\%) } \\
\text { Very good } \\
\text { Good } \\
\text { Poor } \\
\text { Very poor }\end{array}$ & $\begin{array}{l}285(24.0) \\
814(68.5) \\
69(5.8) \\
21(1.8)\end{array}$ & $\begin{array}{l}74(23.9) \\
213(68.4) \\
20(6.5) \\
3(1.0)\end{array}$ & $\begin{array}{l}211(24.0) \\
601(68.4) \\
49(5.6) \\
18(2.0)\end{array}$ & 0.579 \\
\hline PAID-5, median (IQR) & $4(6)$ & $6(7)$ & $3(5)$ & $<0.001$ \\
\hline
\end{tabular}

Abbreviations: ADDQoL, Audit of Diabetes-Dependent Quality of Life; BIPQ, Brief Illness Perception Questionnaire; BMI, body mass index; EQ-5D, EuroQol 5D; LDL, low-density lipoprotein; PAID, Problem Areas In Diabetes; PAM, Patient Activation Measure.

insulin hardly leads to hypoglycemic events and does not require insulin dose adjustments for exercise or carbohydrate intake. On the other hand, a basal-bolus regimen may require a greater level of self-care: patients need to monitor their glucose levels more closely, inject insulin four times daily, handle hypoglycemic events and adjust insulin dosages based on physical activity and carbohydrate intake. In addition, no data on the duration of insulin therapy were available; 
Table 2 Multivariate analyses of factors associated with patient activation

\begin{tabular}{|c|c|c|c|}
\hline & $\beta$ & $95 \% \mathrm{Cl}$ & $P$-value \\
\hline Insulin use & 0.22 & -1.53 to 1.97 & 0.809 \\
\hline Age (every year increase) & -0.04 & -0.12 to 0.03 & 0.274 \\
\hline $\begin{array}{l}\text { Educational level } \\
\text { Low } \\
\text { Middle } \\
\text { High }\end{array}$ & $\begin{array}{l}-3.33 \\
-1.18 \\
\text { Ref. }\end{array}$ & $\begin{array}{l}-5.13 \text { to }-1.54 \\
-2.86 \text { to } 0.40 \\
\text { Ref. }\end{array}$ & $\begin{array}{l}<0.001 \\
0.166\end{array}$ \\
\hline Smoking & -0.35 & -2.20 to 1.50 & 0.708 \\
\hline Alcohol & -0.40 & -1.69 to 0.89 & 0.542 \\
\hline $\begin{array}{l}\text { Diabetes duration (every year } \\
\text { increase) }\end{array}$ & 0.05 & -0.03 to 0.14 & 0.208 \\
\hline Macrovascular complications & -0.94 & -2.40 to 0.52 & 0.206 \\
\hline BMI (every kg/m² increase) & -0.05 & -0.18 to 0.07 & $0.40 \mathrm{I}$ \\
\hline SBP (every $\mathrm{mmHg}$ increase) & -0.03 & -0.07 to 0.02 & 0.232 \\
\hline HbAlc (every \% increase) & -0.22 & -0.97 to 0.54 & \multirow[t]{2}{*}{0.572} \\
\hline $\mathrm{HbAlc}$ (every $\mathrm{mmol} / \mathrm{mol}$ increase) & -0.02 & -0.09 to 0.05 & \\
\hline LDL (every mmol/L increase) & 0.04 & -0.75 to 0.83 & 0.919 \\
\hline EQ-5D (one unit increase) & 4.37 & 0.90 to 7.85 & 0.014 \\
\hline \multicolumn{4}{|l|}{ BIPQ (one unit increase) } \\
\hline I. Consequence & 0.02 & -0.35 to 0.39 & 0.916 \\
\hline 2. Timeline & -0.71 & -1.00 to -0.42 & $<0.001$ \\
\hline 3. Personal control & 0.38 & 0.03 to 0.73 & 0.033 \\
\hline 4. Treatment control & 0.26 & -0.09 to 0.60 & 0.144 \\
\hline 5. Identity & -0.02 & $-0.4 \mid$ to 0.37 & 0.917 \\
\hline 6. Illness concern & -0.04 & -0.36 to 0.27 & 0.794 \\
\hline 7. Coherence & 1.27 & 0.92 to 1.62 & $<0.001$ \\
\hline 8. Emotional representation & -0.16 & -0.50 to 0.18 & 0.362 \\
\hline ADDQoL (every unit increase) & 0.22 & -0.58 to 1.02 & 0.586 \\
\hline $\begin{array}{l}\text { Social support } \\
\text { Very good } \\
\text { Good } \\
\text { Poor } \\
\text { Very poor }\end{array}$ & $\begin{array}{l}4.64 \\
\text { Ref. } \\
-1.00 \\
5.23\end{array}$ & $\begin{array}{l}3.12 \text { to } 6.16 \\
\text { Ref. } \\
-3.85 \text { to } 1.84 \\
0.46 \text { to } 10.00\end{array}$ & $\begin{array}{l}<0.001 \\
0.488 \\
0.032\end{array}$ \\
\hline PAID (every unit increase) & -0.13 & -0.37 to 0.11 & 0.299 \\
\hline
\end{tabular}

Notes: Reference categories: macrovascular complications absent; alcohol: no; smoking: no; and insulin: no. Ref, reference category; $\beta$, regression coefficient.

Abbreviations: ADDQoL, Audit of Diabetes-Dependent Quality of Life; BIPQ, brief illness perception questionnaire; BMI, body mass index; EQ-5D, EuroQol 5D; LDL, low-density lipoprotein; PAID, Problem Areas In Diabetes; PAM, Patient Activation Measure; LDL, low-density lipoprotein; Ref, reference.

patient activation might increase over time as an individual becomes more comfortable with a new treatment. ${ }^{32}$ Patient activation in chronically ill individuals is not stable over time, but increases and decreases within individuals. ${ }^{28}$ Unfortunately, time could not be taken into account in this cross-sectional study, and due to the cross-sectional design of our study, we can only speculate about causality.

Furthermore, the social support statement consisted of a single question rather than a validated questionnaire. Therefore, we cannot be sure that it adequately captures the concept of "social support". Finally, our largest regression coefficient was 1.27 , specifically for every unit increase on the coherence domain of the BIPQ. This means that the PAM-13 score covered a maximum possible difference of 12.7, when an individual improves from no understanding to an optimal understanding of his or her diabetes.

Conversely, our large and representative sample can be considered a strength of the study ${ }^{14}$ and the levels of patient activation were comparable to other Dutch populations with type 2 diabetes mellitus. ${ }^{3,13,24}$ 


\section{Comparison to literature and interpretation}

Comparable to this study, a previous study, performed among 1,615 primary care type 2 diabetes patients and conducted in the Netherlands, found no association between patient activation and insulin use. ${ }^{13}$ In contrast, an Australian study found that individuals on insulin therapy had a lower level of patient activation. ${ }^{12}$ This study, however, performed a univariable analysis in a subset of 1,853 patients with consistently low or high patient activation over a period of 3 years. This might have resulted in the selection of an unrepresentative group, since patient activation in chronically ill individuals is not stable over time. ${ }^{28}$

We also analyzed which factors were associated with patient activation. However, since this was not the primary aim of the study, these results should be interpreted with caution. A low level of activation was associated with a more negative illness perception, both in our study population and in another study. ${ }^{13}$ Our finding that people who expected their illness to persist were less activated is quite concerning, since a lower activation level might result in worse health-related outcomes. ${ }^{9}$ The need for adequate patient education is emphasized by the finding that those who believe they have greater control over their illness and those who feel they have a better understanding of their illness, both showed a higher level of activation. Additional analysis showed that, for individuals on insulin therapy, the association between patient activation and perceived treatment control was more positive when compared to those not on insulin therapy. Compared to oral antihyperglycemic agents, insulin lowers blood glucose levels more rapidly after administration. Additionally, individuals on insulin therapy are more likely to perform self-monitoring of blood glucose. This may result in more direct feedback on their physical and dietary habits and on their therapy compared to people on oral antihyperglycemic agents. This in turn might explain the differing association between patient activation and perceived treatment control we found. However, the differences between those on insulin and those not on insulin should be interpreted cautiously, since we performed multiple comparisons and the $P$-values were only marginally statistically significant.

Concordant with our findings, other studies also found that individuals with a lower level of education are likely to have a lower level of activation, and those with a better health status are likely to be more activated. ${ }^{24,27,28}$ However, the association between health status and patient activation differed for those on insulin therapy compared to those not on insulin therapy.

In this study, individuals with strong social support were more activated than those with moderate social support, a finding comparable to other studies. ${ }^{24,26}$ Curiously, those with little social support were also more activated compared to those with moderate support. Simply reasoning along the lines "the more social support, the greater the patient activation" seems inadequate; individuals with very little social support may need to be independent in multiple aspects of life, eg, because they are living alone and, therefore, could have a higher level of patient activation. ${ }^{33}$ An additional analysis suggested that the association between social support and patient activation differs depending on insulin therapy. This suggests that while insulin use plays no role in overall patient activation, within individuals on insulin therapy vs individuals not on insulin therapy, patient activation is explained by different determinants.

\section{Implications}

Since illness perception and social support were associated with patient activation, health care providers could explore these factors when aiming to increase patient activation. We found that patient activation is associated with contextual factors. This finding supports the need for holistic patientcentered diabetes care in which person-related factors and patient preferences should be taken into account, in addition to disease-related factors. ${ }^{14,34,35}$

\section{Conclusion}

Insulin use appears to play no role in the activation level of patients with type 2 diabetes mellitus. This finding accords with earlier research. Those with a better health status, very good or very poor social support, those who felt they had greater control over their illness and those who felt they had a better understanding of their illness, all had a higher activation level. Individuals with a lower educational level and those who expected their illness to persist showed a lower activation level. Compared to those on other therapies, patient activation among those on insulin therapy was partly explained by different determinants.

\section{Acknowledgments}

This work was supported by a grant from the Innovation Fund of the Dutch Health Insurance Companies (grant number: 2961) and a grant from the Diabetes Fund, the Netherlands (grant number: 2015.08.1858). Neither the Dutch Health 
Insurance Companies nor the Diabetes Fund was involved in the study design, data collection, analysis and interpretation of the data, writing the manuscript and deciding to submit the article for publication.

\section{Disclosure}

AMB reports an unrestricted grant from Sanofi-Aventis, outside the submitted work. GEHMR received an unrestricted research grant from Sanofi Aventis and fees from Novo Nordisk for consultancy and lecturing, outside the submitted work. The authors report no other conflicts of interests in this work.

\section{References}

1. Holman H, Lorig K. Patient self-management: a key to effectiveness and efficiency in care of chronic disease. Public Health Rep. 2004; 119(3):239-243.

2. Hendriks M, Plass AM, Heijmans M, Rademakers J. Minder Zelfmanagementvaardigheden, Dus Meer Zorggebruik?; NIVEL:2013.

3. Hendriks M, Rademakers J. Relationships between patient activation, disease-specific knowledge and health outcomes among people with diabetes; a survey study. BMC Health Serv Res. 2014;14(1):393.

4. Shortell SM, Poon BY, Ramsay PP, et al. A multilevel analysis of patient engagement and patient-reported outcomes in primary care practices of accountable care organizations. J Gen Intern Med. 2017;32(6):640-647.

5. Hibbard JH, Mahoney ER, Stockard J, Tusler M. Development and testing of a short form of the patient activation measure. Health Serv Res. 2005;40(6 Pt 1):1918-1930.

6. Greene J, Hibbard JH. Why does patient activation matter? An examination of the relationships between patient activation and health-related outcomes. J Gen Intern Med. 2012;27(5):520-526.

7. Hibbard JH, Stockard J, Mahoney ER, Tusler M. Development of the Patient Activation Measure (PAM): conceptualizing and measuring activation in patients and consumers. Health Serv Res. 2004;39(4 Pt 1): $1005-1026$.

8. Rask KJ, Ziemer DC, Kohler SA, Hawley JN, Arinde FJ, Barnes CS. Patient activation is associated with healthy behaviors and ease in managing diabetes in an indigent population. Diabetes Educ. 2009; 35(4):622-630.

9. Sacks RM, Greene J, Hibbard J, Overton V, Parrotta CD. Does patient activation predict the course of type 2 diabetes? A longitudinal study. Patient Educ Couns. 2017;100(7):1268-1275.

10. Hibbard JH, Greene J, Sacks RM, Overton V, Parrotta C. Improving Population Health Management Strategies: Identifying Patients Who Are More Likely to Be Users of Avoidable Costly Care and Those More Likely to Develop a New Chronic Disease. Health Serv Res. 2017;52(4):1297-1309.

11. Selvin E, Parrinello CM, Daya N, Bergenstal RM. Trends in Insulin Use and Diabetes Control in the U.S.: 1988-1994 and 1999-2012. Diabetes Care. 2016;39(3):e33-e35.

12. Aung E, Donald M, Williams GM, Coll JR, Doi SA. Joint influence of patient-assessed chronic illness care and patient activation on glycaemic control in type 2 diabetes. Int J Qual Health Care. 2015;27(2):117-124.

13. Hendriks SH, Hartog LC, Groenier KH, et al. Patient activation in type 2 diabetes: does it differ between men and women? J Diab Res. 2016;2016(28):1-8.

14. Rutten GEHM, van Vugt HA, de Weerdt I, de Koning E. Implementation of a structured diabetes consultation model to facilitate a personcentered approach: results from a nationwide dutch study. Diabetes Care. 2018;41(4):688-695.

15. Insignia Health. Patient activation measure (PAM) 13, license materials. Insignia Health, LLC; 2015. Available from: http://solihulltogether.co.uk/images/Patient_Activation/UK_PAM_13.pdf. Accessed December 21, 2018.
16. Rademakers J, Nijman J, van der Hoek L, Heijmans M, Rijken M. Measuring patient activation in the Netherlands: translation and validation of the American short form Patient Activation Measure (PAM13). BMC Public Health. 2012;12(1):577.

17. The Euroqol Group. EuroQol - a new facility for the measurement of health-related quality of life. Health Policy. 1990;16(3):199-208.

18. Bradley C, Todd C, Gorton T, Symonds E, Martin A, Plowright R. The development of an individualized questionnaire measure of perceived impact of diabetes on quality of life: the ADDQoL. Qual Life Res. 1999; 8(1-2):79-91.

19. de Raaij EJ, Schröder C, Maissan FJ, Pool JJ, Wittink H. Cross-cultural adaptation and measurement properties of the Brief Illness Perception Questionnaire-Dutch Language Version. Man Ther. 2012;17(4): 330-335.

20. Mcguire BE, Morrison TG, Hermanns N, et al. Short-form measures of diabetes-related emotional distress: the Problem Areas in Diabetes Scale (PAID)-5 and PAID-1. Diabetologia. 2010;53(1):66-69.

21. Toobert DJ, Hampson SE, Glasgow RE. The summary of diabetes self-care activities measure: results from 7 studies and a revised scale. Diabetes Care. 2000;23(7):943-950.

22. Remmers C, Hibbard J, Mosen DM, Wagenfield M, Hoye RE, Jones C. Is patient activation associated with future health outcomes and healthcare utilization among patients with diabetes? J Ambul Care Manage. 2009;32(4):320-327.

23. Rogvi S, Tapager I, Almdal TP, Schiøtz ML, Willaing I. Patient factors and glycaemic control - associations and explanatory power. Diabet Med. 2012;29(10):e382-e389.

24. Bos-Touwen I, Schuurmans M, Monninkhof EM, et al. Patient and disease characteristics associated with activation for self-management in patients with diabetes, chronic obstructive pulmonary disease, chronic heart failure and chronic renal disease: a cross-sectional survey study. PLoS One. 2015;10(5): $\mathrm{e} 0126400-\mathrm{e} 0126415$.

25. Chubak J, Anderson ML, Saunders KW, et al. Predictors of 1-year change in patient activation in older adults with diabetes mellitus and heart disease. J Am Geriatr Soc. 2012;60(7):1316-1321.

26. Schiøtz ML, Bøgelund M, Almdal T, Jensen BB, Willaing I. Social support and self-management behaviour among patients with Type 2 diabetes. Diabet Med. 2012;29(5):654-661.

27. Kato A, Fujimaki Y, Fujimori S, et al. Psychological and behavioural patterns of stigma among patients with type 2 diabetes: a cross-sectional study. BMJ Open. 2017;7(3):e013425.

28. Rijken M, Heijmans M, Jansen D, Rademakers J. Developments in patient activation of people with chronic illness and the impact of changes in self-reported health: results of a nationwide longitudinal study in The Netherlands. Patient Educ Couns. 2014;97(3):383-390.

29. Chew BH, Vos R, Mohd-Sidik S, Rutten GE. Diabetes-Related distress, depression and Distress-Depression among adults with type 2 diabetes mellitus in Malaysia. PLoS One. 2016;11(3):e0152095.

30. Wallia A, Molitch ME. Insulin therapy for type 2 diabetes mellitus. JAMA. 2014;311(22):2315-2325.

31. Jin SM, Kim JH, Min KW, et al. Basal-prandial versus premixed insulin in patients with type 2 diabetes requiring insulin intensification after basal insulin optimization: A 24-week randomized non-inferiority trial. J Diabetes. 2016;8(3):405-413.

32. Odawara M, Ishii H, Tajima N, Iwamoto Y. Impact of patient attitudes and beliefs to insulin therapy upon initiation, and their attitudinal changes after initiation: the DAWN Japan study. Curr Med Res Opin. 2016;32(4):681-686.

33. Shin JK, Kim KW, Park JH, et al. Impacts of poor social support on general health status in community-dwelling korean elderly: the results from the korean longitudinal study on health and aging. Psychiatry Investig. 2008;5(3):155-162.

34. Rutten G, Alzaid A. Person-centred type 2 diabetes care: time for a paradigm shift. Lancet Diabetes Endocrinol. 2017;8587(17):10-11.

35. Schmidt-Busby J, Wiles J, Exeter D, Kenealy T. Understanding 'context' in the self-management of type 2 diabetes with comorbidities: A systematic review and realist evaluation. Diabetes Res Clin Pract. 2018;142:321-334. 
Patient Preference and Adherence

Dovepress

\section{Publish your work in this journal}

Patient Preference and Adherence is an international, peer-reviewed, open access journal that focuses on the growing importance of patient preference and adherence throughout the therapeutic continuum. Patient satisfaction, acceptability, quality of life, compliance, persistence and their role in developing new therapeutic modalities and compounds to optimize

Submit your manuscript here: http://www.dovepress.com/patient-preference-and-adherence-journ clinical outcomes for existing disease states are major areas of interest for the journal. This journal has been accepted for indexing on PubMed Central. The manuscript management system is completely online and includes a very quick and fair peer-review system, which is all easy to use. Visit http://www. dovepress.com/testimonials.php to read real quotes from published authors. 